\title{
An RNA polymerase I termination site can stimulate the adjacent ribosomal gene promoter by two distinct mechanisms in Xenopus laevis
}

\author{
Brian McStay and Ronald H. Reeder \\ Basic Sciences Division, Hutchinson Cancer Research Center, Seattle, Washington 98104 USA
}

\begin{abstract}
On the ribosomal genes of Xenopus laevis, the $T 3$ terminator is located $\sim 60$ bp upstream of the $5^{\prime}$ boundary of the gene promoter. We have shown previously that mutation of the terminator simultaneously abolishes termination and impairs initiation by RNA polymerase I. Here, we show that the terminator influences the promoter by two distinct mechanisms. In one mechanism the terminator protects the promoter by preventing polymerase from reading through the initiation complex. In a second mechanism, the terminator interacts directly with the promoter, whether or not termination occurs. This positive interaction requires precise positioning of the terminator relative to the promoter and is sensitive to movement of the terminator by as little as 1 or $2 \mathrm{bp}$. We conclude that the terminator and promoter interact as one interdependent complex.
\end{abstract}

[Key Words: Transcription termination in vitro; promoter occlusion; terminator-promoter interaction; Xenopus laevis ribosomal DNA]

Received October 23, 1989; revised version accepted April 26, 1990.

Xenopus laevis has two transcription units located on each repeating unit of its ribosomal DNA, a characteristic typical of many eukaryotes. One transcription unit is initiated at the gene promoter and has its $3^{\prime}$ end at site T2, which forms the $3^{\prime}$ end of the $40 S$ precursor RNA (Labhart and Reeder 1986). T2 appears to be a terminator that has acquired a single-base mutation allowing polymerase to read through while retaining the ability to form 3' ends (Labhart and Reeder 1990). The other transcription unit initiates at one or more of the spacer promoters and terminates at T3, a full termination element that is located $\sim 60 \mathrm{bp}$ upstream of the gene promoter (Moss 1983; Labhart and Reeder 1986; McStay and Reeder 1986). T3 also appears to be the terminator for transcription that has read through T2. Analysis of mutants of T3, assayed by oocyte injection, has shown that full terminator activity at $\mathrm{T} 3$ requires only the sequence GACTTGCNC (T3 terminator), whereas $\mathrm{N}$ appears to be a neutral base (Labhart and Reeder 1990). Changing the terminal $\mathrm{C}$ to a $\mathrm{G}$ abolishes termination while retaining 3 '-end formation. And this $\mathrm{C} \rightarrow \mathrm{G}$ mutation occurs naturally at site $\mathrm{T} 2$ (the T2 sequence is GACTTGCNG) at the $3^{\prime}$ end of the $40 S$-coding region. Both T3 and T2 specify $3^{\prime}$ ends 15 nucleotides upstream of the T3 and T2 elements, respectively. We have shown recently that a specific DNA-binding protein, Rib 2, must bind to T3 to effect termination (McStay and Reeder 1990).

Termination elements have also been identified in mammalian ribosomal DNA, particularly in the mouse. A series of tandemly repeated terminators (Sal boxes) are located at the $3^{\prime}$ end of the $45 \mathrm{~S}$ precursor-coding region (Grummt et al. 1985), and a single terminator is present upstream of the gene promoter in homology with the location of terminator elements in $X$. laevis (Grummt et al. 1986a; Henderson and Sollner-Webb 1986). A major difference between mouse and frog is that the terminators at the $3^{\prime}$ end of the $45 \mathrm{~S}$ region are not mutated in the mouse and cause efficient termination. In addition, it has been shown in the mouse system that a specific DNA-binding protein, TTF1, interacts with the Sal box and is required for termination (Grummt et al. 1986b; Bartsch et al. 1988).

We have known for some time that mutation of the T3 terminator in $X$. laevis can cause a concomitant decrease in transcription initiation at the adjacent gene promoter (McStay and Reeder 1986). Here, we show that there are at least two distinct mechanisms whereby this terminator-promoter interaction can occur. Evidence for both mechanisms can be observed in vivo, but for detailed study, we found in vitro conditions where each mechanism operates nearly to the exclusion of the other. One mechanism, which we call "promoter protection," is a mechanism in which the terminator protects the initiation complex at the gene promoter from disruption by elongating polymerase reading through from upstream. Evidence that such a protective mechanism is operative for RNA polymerase I promoters has also been published for mouse (Henderson et al. 1989) and for Acanthamoeba (Bateman and Paule 1988).

The second mechanism, which we call "promoter 
stimulation," is a novel one that has been reported so far in only $X$. laevis. We find that under certain conditions, initiation at the promoter is strongly dependent on the terminator being present in precisely its normal location. Moving the terminator closer or farther away by as little as 2 bp has serious effects on initiation. This implies a physical interaction between the proteins that bind to the promoter and the terminator.

\section{Results}

\section{Evidence for both promoter protection and promoter} stimulation can be observed in vivo

To examine T3 terminator effects on the ribosomal gene promoter in vivo, we prepared a series of four templates, as illustrated in Figure 1C. Template A consists of a ribosomal gene promoter, with a single T3 terminator in its normal location, inserted into the vector pGEM3. Template $B$ is identical to $A$, except that the $T 3$ element contains a cluster of point mutations that eliminates its ability to terminate transcription (LS-7, Fig. 2A). Template $\mathrm{C}$ also has a mutated $\mathrm{T} 3$ element upstream of the gene promoter, but in this case, a second functional $\mathrm{T} 3$ has been inserted about one-third of the way around the plasmid circle. Template D is identical to $C$, except that both T3 elements are wild type and functional. Templates A-D were injected individually into $X$. laevis oocytes, along with an equimolar amount of a control plasmid that is similar to template A, except for modifications downstream of the promoter to allow its transcripts to be distinguished from those of the experi- mental templates. Transcription was assayed by an S1 nuclease protection assay.

Evidence that promoter protection can occur in vivo is shown in Figure 1A. By comparing lanes 1 and 2, we saw that mutation of the T3 element immediately upstream of the gene promoter caused a decrease in transcription initiation $(\sim 15$-fold in this experiment $)$ with a concomitant increase in readthrough transcription (full-length probe protection). If this decrease in initiation were due to a lack of promoter protection, we would expect that transcription could be rescued by the placing of an extra, functional terminator anywhere upstream of the promoter. In Figure 1A, lane 3, we saw that, by the placing of an extra T3 element in the plasmid circle, transcription was restored nearly to the wild-type level $\{-70 \%$ of wild type; cf. with lane 1). Decrease in transcription due to mutation of $\mathrm{T} 3$, concomitant increase in readthrough, and rescue of transcription by an extra terminator placed anywhere upstream could be readily explained by the presence of a promoter protection mechanism.

It is significant, however, that the addition of a far upstream terminator to the plasmid does not completely rescue the negative effect of the mutation of $\mathrm{T} 3$ adjacent to the promoter, even though it did completely abolish readthrough (Fig. 1A; cf lanes 3 and 1). As illustrated in Figure 1A (lane 4), restoration to the full wild-type level of transcription required the presence of a functional T3 in its normal location. From this, we deduce that T3, in addition to its protective effect on the promoter, has some other positive influence on transcription that is position dependent and cannot be replaced by a second terminator located far upstream. The characteristics of

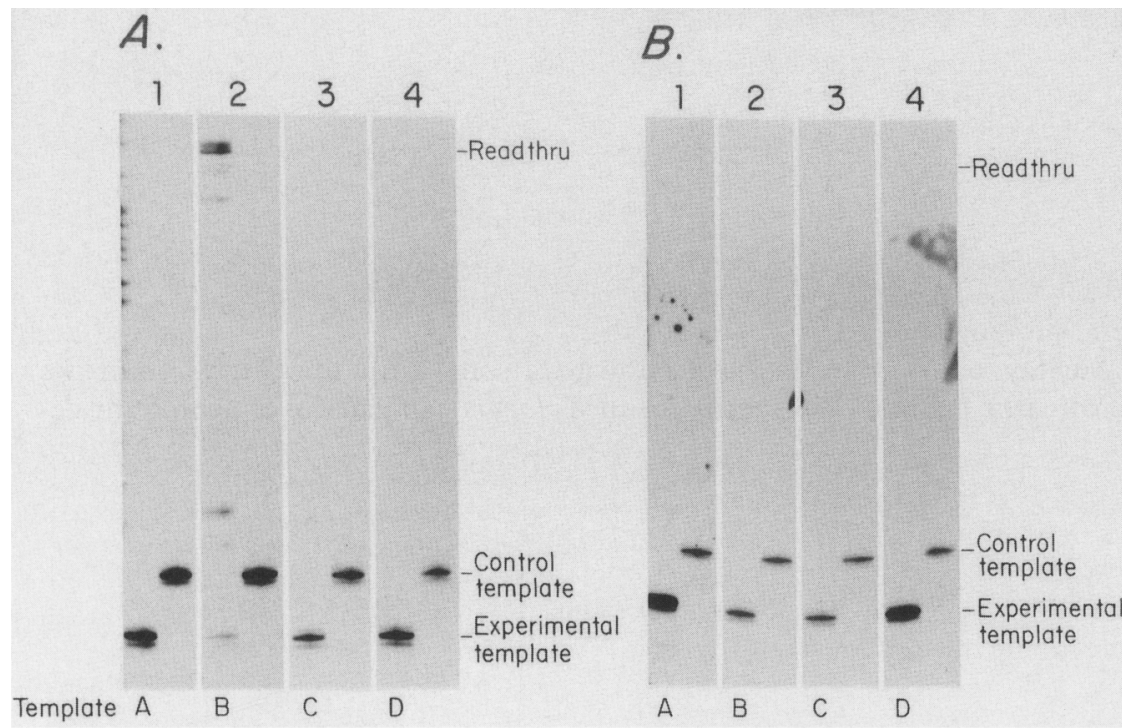

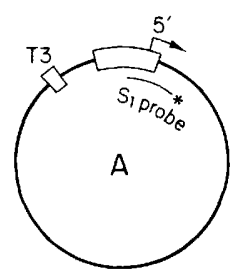
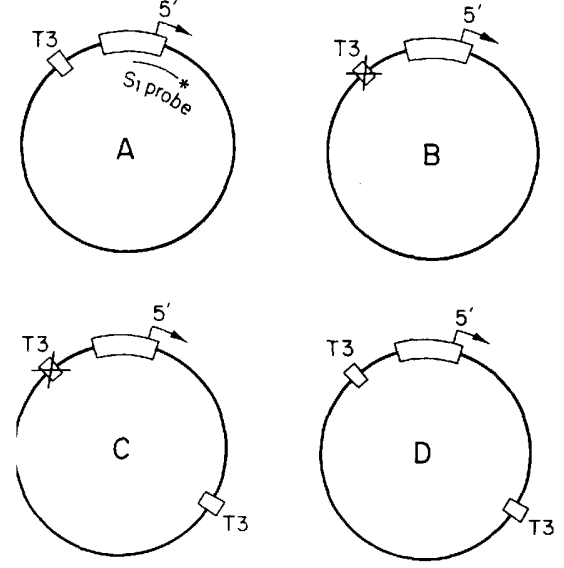

Figure 1. Detection of terminator-promoter interactions in vivo. $(A)$ Oocytes showing primarily a promoter protection response. Templates A-D $(C)$ were mixed individually with an equimolar amount of a control template (pGem52) and injected into $X$. laevis oocytes. Transcription was assayed by S1 nuclease protection. Full-length probe protection indicates readthrough transcription. $(B)$ Oocytes showing primarily a promoter stimulation response (same experiment as in $A$, but with a different batch of oocytes). (C) Structure of plasmid templates used in oocyte injection experiments. Each plasmid contains a single ribosomal gene promoter (initiation site is indicated by $5^{\prime}$ arrow) and various combinations of T3 terminator elements, both wild type and mutated (the mutation is LS-7, shown in Fig. 3). The structure of each of these templates is described more fully in Materials and methods (template A is pGem40, template B is pGemT3LS-7, template C is pTVT3LS-7T3-A, template D is pTV-2453-A). 


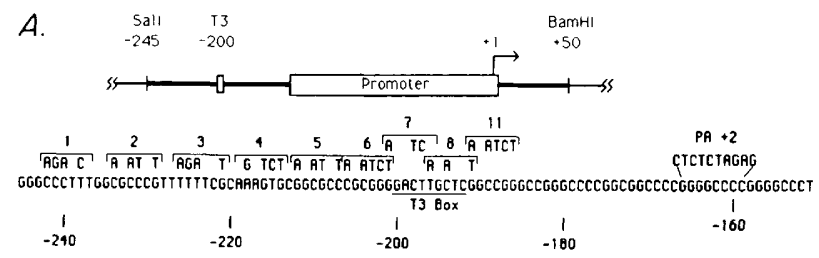

B.

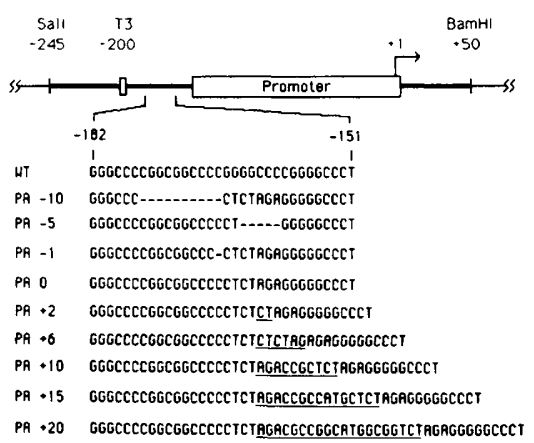

Figure 2. Structure of LS and spacing mutant templates. (A) LS mutants. The starting plasmid for LS mutagenesis was pGem40, a plasmid that contained $X$. laevis rDNA sequences from -245 to +50 , cloned as a Sall-BamHI fragment into the vector pGEM3 (Promega). The structure of this insert is shown; the promoter $(-142$ to +6$)$ and the T3 terminator $(-200$ to -192 ) are depicted by an open box, surrounding ribosomal sequences are indicated by a thick line, and vector sequences are indicated by a thin line. The nucleotide changes present in each of the LS mutants (pGemT3LS-1-11) are shown above the wildtype DNA sequence (nucleotides -245 to -151 ). The location of the T3 terminator is shown below this sequence. Altered nucleotides in pGemPA +2 are also shown. $(B) \mathrm{T} 3$ promoter spacing mutants. The structure of the ribosomal gene insert in pGem40 is shown (labeled as in Fig. 1A). Also shown is the DNA sequence of this plasmid from position -182 to -151 (WT). The equivalent DNA sequences from the plasmid that was used to alter spacing between $\mathrm{T} 3$ and the promoter (PA 0 ) and from those with altered $\mathrm{T} 3$ /promoter spacing $(\mathrm{PA}-10$, $\mathrm{PA}-5, \mathrm{PA}-1, \mathrm{PA}+2, \mathrm{PA}+6, \mathrm{PA}+10, \mathrm{PA}+15, \mathrm{PA}+20)$ are shown below the wild-type sequence. Deleted nucleotides are represented by a dash, and inserted nucleotides are underlined.

this second effect of $\mathrm{T} 3$ are consistent with a promoter stimulation mechanism. In Figure 1A, the magnitude of the putative promoter stimulation effect is modest /only $\sim 30 \%$ of the overall effect of T3 on transcription).

In other oocytes, however, the situation can be reversed, with promoter stimulation accounting for most of the effect of mutation of T3. An experiment with such oocytes is shown in Figure 1B. In this experiment, the same set of templates was injected as in Figure 1A. Once again we observed that mutation of T3 upstream of the promoter had a negative effect on transcription initiation (a fivefold decrease; Fig. 1B, cf. lanes 1 and 2). However, very little of this negative effect could be attributed to a promoter protection mechanism, because the addition of a second $\mathrm{T} 3$ element far upstream produced almost no rescue of transcription (Fig. 1B, cf. lanes 2 and 3). It is also of interest to note in Figure 1B (lane 2) that mutating T3 caused very little increase in transcription readthrough. In this batch of oocytes the only manipulation that restored transcription was the restoration of a wild-type T3 element to its normal location (Fig. 1B, cf. lanes 3 and 4).

Most oocytes yielded a response to mutation of T3 that was intermediate between the two extremes illustrated in Figure 1, A and B. From many experiments of this type, we conclude that both promoter protection and promoter stimulation mechanisms are probably operating in living oocytes. However, variability inherent in the injection assay, as well as variability in the physiological state of the oocytes, makes it very difficult to study either mechanism in detail. To circumvent this problem, we defined in vitro conditions in which one of these two mechanisms operates nearly to the exclusion of the other. This has allowed us to prove that they are two distinct mechanisms, and it has allowed us to learn more about how they operate.

\section{In vitro transcription conditions that favor promoter protection can be defined}

In vitro transcription extracts for RNA polymerase I transcription were prepared as S-100 extracts from $X$. laevis cultured kidney cells. In the course of learning to make these extracts we observed that the conditions under which the extract is preincubated with DNA can have a significant effect on the response of the extract to mutation of $\mathrm{T} 3$.

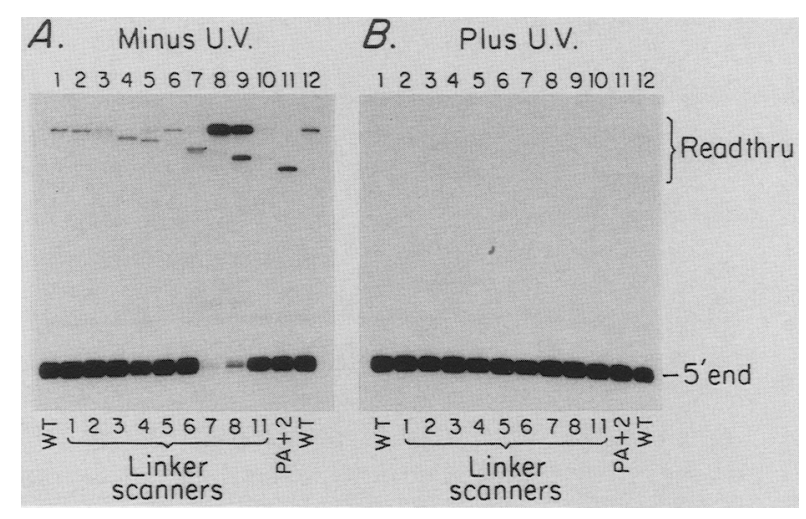

Figure 3. Sequence requirements for the promoter protection effect. (A) Minus UV transcription reactions contained $20 \mu \mathrm{l}$ of DEAE $0.35 \mathrm{M}, 10 \mu \mathrm{l}$ of DEAE flowthrough, and $400 \mathrm{ng}$ of supercoiled template. The templates were pGem 40 (WT, lanes 1 and 12), pGemT3LS-1 (lane 2), pGemT3LS-2 (lane 3), pGemT3LS-3 (lane 4), pGemT3LS-4 (lane 5), pGemT3LS-5 (lane 6), pGemT3LS-6 (lane 7), pGemT3LS-7 (lane 8), pGemT3LS-8 (lane 9), pGemT3LS-11 (lane 10), and pGemPA+2 (lane 11). The DNA sequence changes present in each of the LS mutations are shown in Fig. 2. Transcripts were analyzed by S1 nuclease protection. The template used in each reaction is shown under each lane as appropriate. Correctly initiated and readthrough transcripts are labeled 5' end and "Readthru," respectively. (B) Plus UV transcription reactions and templates were exactly as described above, except that all templates were treated with UV prior to transcription. 
To obtain a promoter protection response, the extract was mixed with a relatively high amount of template DNA (usually $\sim 400 \mathrm{ng}$ of template per $20 \mu \mathrm{l}$ of extract) and incubated on ice for $10 \mathrm{~min}$; the reaction was started by the addition of nucleotides. Under these preincubation conditions, the amount of template required for optimum transcription is also high, in the range of $400 \mathrm{ng} / 20 \mu \mathrm{l}$ of extract.

The response to mutation of $\mathrm{T} 3$ and surrounding sequence under promoter protection conditions is shown in Figure 3. Starting with template A (Fig. 1), we prepared a series of linker-scanner (LS) mutants around the T3 element (shown in Fig. 2A) and assayed them under promoter protection conditions by $\mathrm{S} 1$ nuclease protection. As shown in Figure 3A, the only mutations that had any effect on transcription initiation are LS-7 and LS-8, both of which cause a severe (10- to 20-fold) decrease in initiation with a concomitant increase in readthrough transcription. LS-7 and LS-8 are also the only two mutants that altered nucleotides within the T3 terminator, suggesting that the protein bound to the terminator is involved in the protective effect.

The positive effect of $\mathrm{T} 3$ on initiation under these conditions is consistent with a protection mechanism in which the terminator simply prevents damage to the promoter by polymerase that has transcribed all around the plasmid circle. If this interpretation were correct, we should have been able to mimic the protective effect of $\mathrm{T} 3$ by placing additional terminators at any place on the plasmid circle. In Figure 3B we assayed the same set of LS mutants, again under promoter protection conditions, but this time all of the templates were irradiated with UV light before they were added to the transcription extract. Numerous studies have shown UV damage to the template acts as termination sites for RNA polymerase I (Hackett and Sauerbier 1975; Henderson et al. 1989; Labhart and Reeder 1989; Lucchini and Reeder 1989). As shown in Figure 3B, UV irradiation completely rescued the negative effect of LS-7 and LS-8 under promoter protection conditions.

To make the same point another way, we inserted a second T3 terminator within the plasmid circle (Fig. 1, templates C and D/ and found that this also rescued LS-7 when assayed under promoter protection conditions (data not shown). Thus, under promoter protection conditions in vitro, we obtained a response to mutation of $\mathrm{T} 3$ that is similar to that obtained in vivo with the batch of oocytes assayed in Figure 1A. The only difference is that we almost completely suppressed any contribution from a second, presumable promoter-stimulation mechanism in vitro. Under these conditions, the $X$. laevis extract behaved essentially the same as mouse extracts that have been used to demonstrate promoter interference in mammals (Henderson et al. 1989).

\section{Alternate preincubation conditions favor promoter stimulation}

To observe promoter stimulation during in vitro transcription, the extract was first preincubated with nonspecific DNA (200-400 ng of pGEM3 vector DNA per

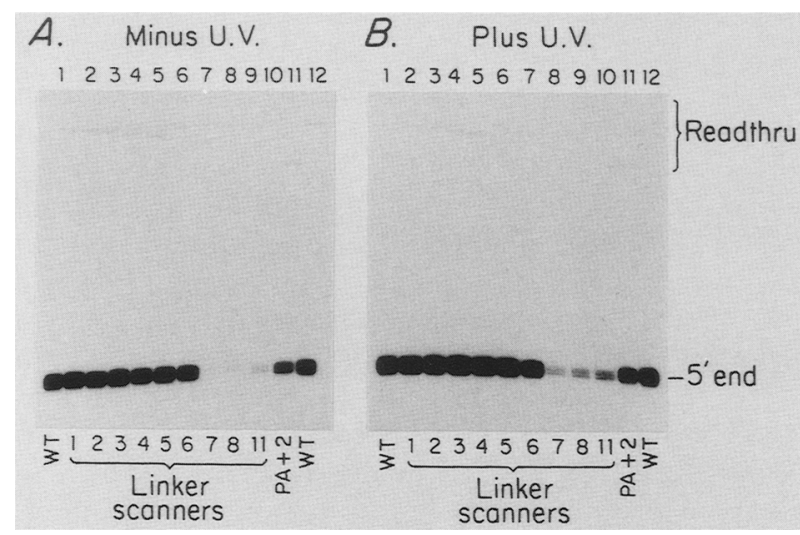

Figure 4. Sequence requirements for promoter stimulation effect. (A) Minus UV transcription reactions contained $20 \mu \mathrm{l}$ of DEAE $0.35 \mathrm{M}$ and $10 \mu \mathrm{l}$ of DEAE flowthrough. This mixture was preincubated on ice for $10 \mathrm{~min}$ with nonspecific DNA 1400 ng pGem3) prior to the addition of supercoiled template (100 ng). The templates were pGem40 (WT, lanes 1 and 12), pGemT3LS-1 (lane 2), pGemT3LS-2 (lane 3), pGemT3LS-3 (lane 4), pGemT3LS-4 (lane 5), pGemT3LS-5 (lane 6), pGemT3LS-6 (lane 7), pGemT3LS-7 (lane 8), pGemT3LS-8 (lane 9), pGemT3LS-11 (lane 10), and pGemPA + 2 (lane 11). (B) Plus UV transcription reactions were as above, except that templates were treated with UV prior to transcription.

$20 \mu \mathrm{l}$ of extract for $10 \mathrm{~min}$ on ice). Template DNA was then added $(50-100 \mathrm{ng})$ and incubated for an additional 10 min on ice before the reaction was started by the addition of nucleotides. Under these conditions, the observed template optimum was also lower (in the range of $50-100 \mathrm{ng}$ template per $20 \mu \mathrm{l}$ of extract).

In Figure 4, the same set of LS mutants were assayed under promoter stimulation conditions. Once again we observed (Fig. 4A) that mutation of the T3 element (LS-7 and LS-8) had a severe effect on initiation ( $\sim 50$-fold down). Under these conditions, however, there was an additional requirement for sequences immediately adjacent to the T3 element (LS-11), and we saw little increase in readthrough upon mutation of $\mathrm{T} 3$.

The most dramatic difference, however, was the fact that when additional terminators were added to the plasmid circle the $\mathrm{T} 3$ mutants were not rescued under promoter stimulation conditions. Figure 4B shows that UV irradiation did not rescue and we have also found that addition of more $\mathrm{T} 3$ elements to the plasmid does not rescue (data not shown). As we will show below (Fig. 6), the effect of T3 under promoter stimulation conditions is most likely the result of a precise interaction between factors binding to the terminator and to the promoter and does not involve termination per se. We think that this effect of the T3 terminator was probably the dominant effect in the batch of oocytes assayed in Figure 1B.

Both promoter protection and promoter stimulation require the binding of Rib 2 binding to the T3 element

We have shown elsewhere that $X$. laevis extracts contain a DNA-binding factor, Rib 2 , which produces spe- 
cific footprints over the T3 terminator (McStay and Reeder 1990). Mutations that damage termination also damage the Rib 2 footprint. Double-stranded oligonucleotides containing the T3 sequence competed for termination and also competed for the Rib 2 footprint. Therefore, we concluded that transcription termination by $X$. laevis RNA polymerase I requires the binding of Rib 2 to the T3 element.

In Figure 5 we present evidence that in addition to being necessary for termination, the binding of Rib 2 to the T3 element is also required for both the promoter protection and stimulation effects. In Figure 5A, lanes $1-4$, transcription under promoter protection conditions was competed with increasing amounts of a doublestranded oligonucleotide containing a wild-type T3 sequence. Competition caused a decrease in the initiation signal, as well as an increase in readthrough. This is essentially the same response that is seen upon mutation of T3 under protection conditions (cf. Fig. 3A). In Figure $5 \mathrm{~A}$, lanes $5-8$, competition with an oligonucleotide carrying the LS-7 mutation had no effect on either initiation or readthrough.

In Figure 5B, the same competition experiment was repeated under promoter stimulation conditions. In lanes 1-4, we see that competition with the wild-type oligonucleotide had a severe effect on initiation (but little increase in readthrough), whereas lanes 5-8 show that competition with the mutant oligonucleotide had no effect. Competition with the wild-type T3 oligonucleotide had a more severe effect under stimulation conditions, probably because the preincubation conditions were more effective in eliminating nonspecific DNAbinding proteins from the reaction. Comparably severe (but still specific) effects on initiation could be observed under protection conditions simply by use of higher amounts of the wild-type competitor.

From this experiment we conclude that both promoter protection and promoter stimulation require the binding of Rib 2 to the T3 element.

\section{Promoter stimulation requires precise positioning of the T3 element relative to the promoter}

Experiments shown so far suggest that promoter protection is a mechanism in which T3 (or UV damage) can afford protection when placed at almost any location upstream of the promoter. In contrast, promoter stimulation requires more precise positioning of the $\mathrm{T} 3$ element. To examine this requirement for $\mathrm{T} 3$ positioning more closely, we have made a series of constructs in which the T3 element was moved closer to or farther away from the gene promoter (Fig. 2B). These constructs were made by first introducing a unique $\mathrm{XbaI}$ site between $\mathrm{T} 3$ and the promoter without changing the spacing between those two elements (construct PA 0). $\mathrm{PA} 0$ was then cut at this $\mathrm{XbaI}$ site, and additional nucleotides were either inserted or removed. The net result was a series of constructs in which $\mathrm{T} 3 \mathrm{~h}$ had been moved over the range of -10 to $+20 \mathrm{bp}$ relative to its normal position upstream of the promoter.

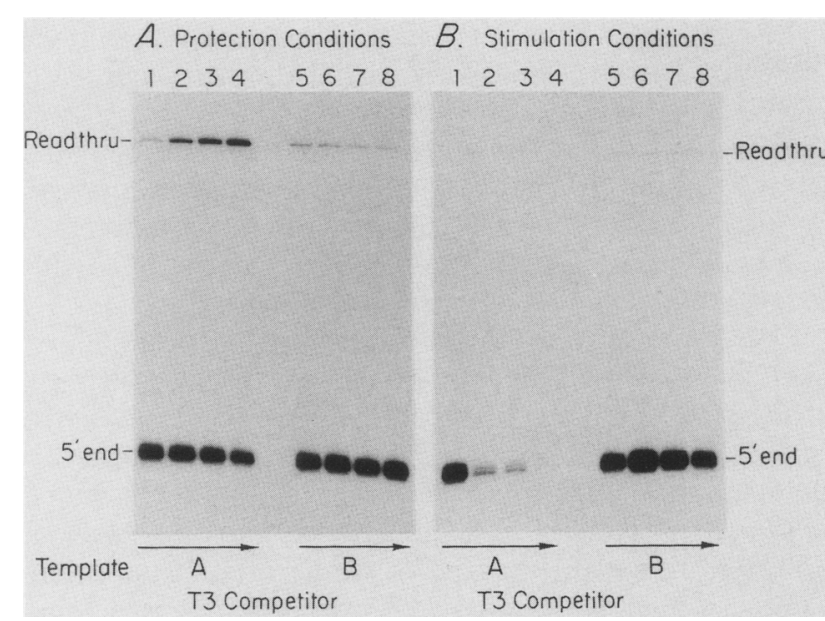

Figure 5. Promoter protection and stimulation effects are competed specifically by the same T3 oligonucleotide. $(A)$ Promoter protection. The plasmid pGem 40 was transcribed under promoter protection conditions (using recombined DEAE 0.35 and flowthrough fractions/ with increasing amounts of either a wild-type T3 oligonucleotide competitor or mutant T3 oligonucleotide competitor. Reactions in lanes 1-4 contained, respectively, $0,200,400$, and $600 \mathrm{ng}$ of wild-type competitor. Reactions in lanes 5-8 contained, respectively, 0, 200, 400, and $600 \mathrm{ng}$ of mutant competitor. Competing oligonucleotides were double-stranded and polymerized by ligation up to $2 \mathrm{~kb}$ in length. The wild-type and mutant oligonucleotides represent the sequences from -207 to -187 of the plasmid pGem 40 and pGemT3LS-7, respectively (for sequence, see Materials and methods). (B) Promoter stimulation. The plasmid pGem40 was transcribed under promoter stimulation conditions with an increasing amount of the wild-type and mutant T3 oligonucleotides described above. Reactions in lanes $1-4$ contained, respectively, $0,50,100$, and $200 \mathrm{ng}$ of wild-type competitor. Reactions in lanes 5-8 contained, respectively, $0,50,100$, and $200 \mathrm{ng}$ of mutant competitor.

When the series of position mutants was assayed under promoter protection conditions (Fig. 6A), they were all essentially neutral in their effect on initiation, and there was no effect on the levels of readthrough transcription (data not shown). This is what would be expected if the only function of T3 under these conditions was to terminate transcription and thereby protect the promoter. These results also agree with the conclusion that $\mathrm{T} 3$ can perform its protection (i.e., termination) function when placed at any distance upstream of the promoter.

When the same series of mutants was assayed under promoter stimulation conditions, a strikingly different result was obtained. Figure 6, B and C, shows two independent experiments, the results of which are combined in the graph shown in Figure 6D. For these experiments, all of the templates were UV-irradiated to eliminate any possible complications resulting from promoter protection. The only position mutant that was neutral was the 0-bp push apart (see legend to Fig. 6). All others have more or less severe negative effects on initiation, in- 

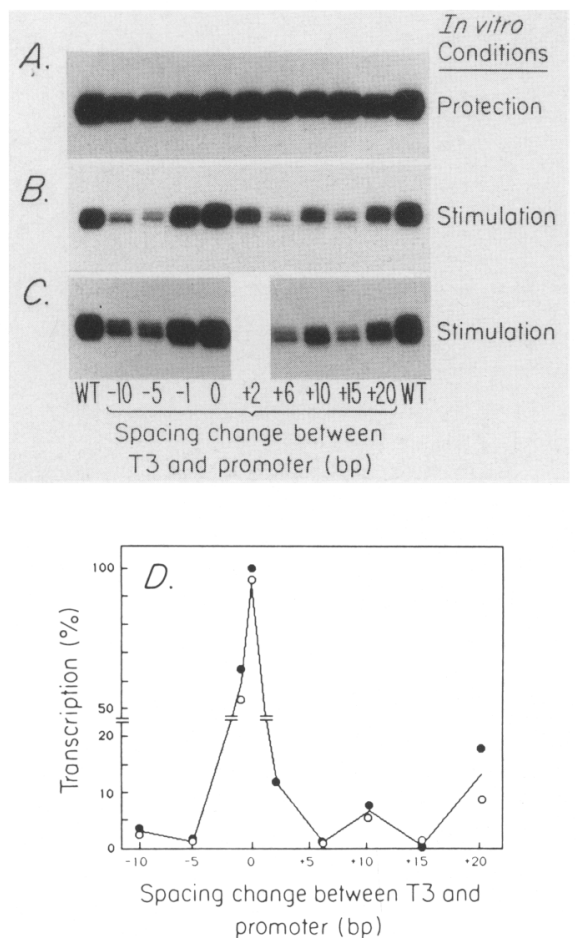

Figure 6. Effect of spacing changes between $\mathrm{T} 3$ and the promoter. (A) Promoter protection. The plasmids pGem40 (WT), pGemPA - 10, pGemPA - 5, pGemPA - 1, pGemPA 0, pGem$\mathrm{PA}+2, \quad \mathrm{pGemPA}+6, \quad \mathrm{pGemPA}+10, \quad \mathrm{pGemPA}+15$, and pGemPA +20 were transcribed under promoter protection conditions futilizing recombined DEAE $0.35 \mathrm{M}$ and flowthrough fractions). ( $B$ and $C$ ) Promoter stimulation. The plasmids pGem40 (WT), pGemPA-10, pGemPA - 5, pGemPA-1, pGemPA 0, pGemPA +2, pGemPA + 6, pGemPA + 10, pGemPA +15 , and $p G e m+20$ were transcribed under promoter stimulation conditions. Only the initiation signals are shown for each experiment. Gels were aligned, and the spacing change between T3 and the promoter in the transcription template is shown below each lane as appropriate. $(D)$ The transcription signal from each of the pGemPA constructs under stimulation conditions was expressed as a percentage of that from pGem 40 and plotted against the number of nucleotides that $\mathrm{T} 3$ and the promoter have been pulled closer together $(-)$ or pushed apart $(+1$. Transcription signals were quantified by image analysis of multiple exposures of each gel, as described in Materials and methods. (O) Results of the experiment shown in $B,(O)$ results of the experiment shown in $C$.

cluding the -1 and +2 mutants. From this set of results we conclude that promoter stimulation by $\mathrm{T} 3$ is exquisitely sensitive to position relative to the promoter. The simplest interpretation of this data is that proteins bound to both $\mathrm{T} 3$ and the promoter must interact for the promoter stimulation mechanism to function.

Closer inspection of Figure 6 reveals that although any movement of T3 from its normal position was deleterious, a partial rescue of initiation occurred when the distance was changed in units of $10 \mathrm{bp}$ (at $-10,0,+10$, and $+20 \mathrm{bp}$ ). This suggests that proteins binding to the promoter and to T3 must be on the same side of the
DNA helix for optimal interaction. However, distance is still critical, and although being on the correct side of the helix helps, it cannot completely compensate for incorrect spacing.

\section{Use of promoter domains differs under protection versus stimulation conditions}

It is a common observation that the requirement for different promoter domains can be varied by changing the conditions of in vitro transcripton. Because the mechanism of promoter stimulation appears to involve an interaction between the terminator and the promoter, we decided to examine the utilization of promoter domains under protection versus stimulation conditions. To do this, we assayed a set of promoter LS mutations (described previously in Reeder et al. 1987) under both sets of conditions; the results are shown in Figure 7.

Under protection conditions, Figure 7A (top), we saw a result that was in general agreement with our previously reported in vitro assay of these mutants (Reeder et al. 1987). The most severe mutant was LS $-142 /-133$, which defined the extreme 5 ' boundary of the promoter. There was a lesser, but still significant, effect of mutation of the region of the promoter that shares sequence homology with the 60/81-bp enhancer elements located in the intergenic spacer (LS-111/-102), and LS-83/75 was neutral (or slightly stimulatory). The rest of the promoter, including the region around the site of initiation, displayed sensitivities to mutation ranging from 2to 10 -fold.

Under stimulation conditions, Figure 7A (bottom), most of the promoter showed the same general sensitivity to mutation as was seen under protection conditions. (For convenience, we plotted the ratio of the signals obtained under each set of conditions at the bottom as Fig. 7B.) The striking exception was in the domain surrounding the initiation site. LS $-17 /-8$, LS $-7 /+3$, and LS $+2 /+10$ all showed greatly reduced transcription under stimulation conditions, as compared to protection conditions $(30-, 26-$, and 9-fold, respectively).

A plausible interpretation of these results is that protein(s) bound to the initiation region are the ones that must interact with Rib 2 (and the T3 element) to obtain efficient initiation under stimulation conditions. In contrast, under protection conditions, initiation can proceed by use of other promoter domains that do not interact with $\mathrm{T} 3$.

Time course of transcription under promoter protection and promoter stimulation conditions

Figure $8 \mathrm{~A}$ shows the time course of transcript accumulation under promoter protection conditions. When a promoter with a wild-type $\mathrm{T} 3$ was used, transcription proceeded with reasonable linearity for nearly $3 \mathrm{hr}$. A low level of readthrough was also detected which, from its kinetics, we suspect was largely due to nonspecific initiation. When a promoter with a mutant T3 element 
A.

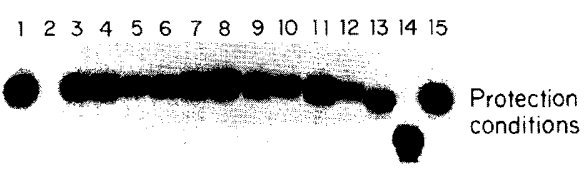

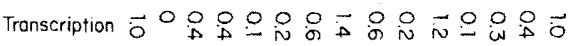
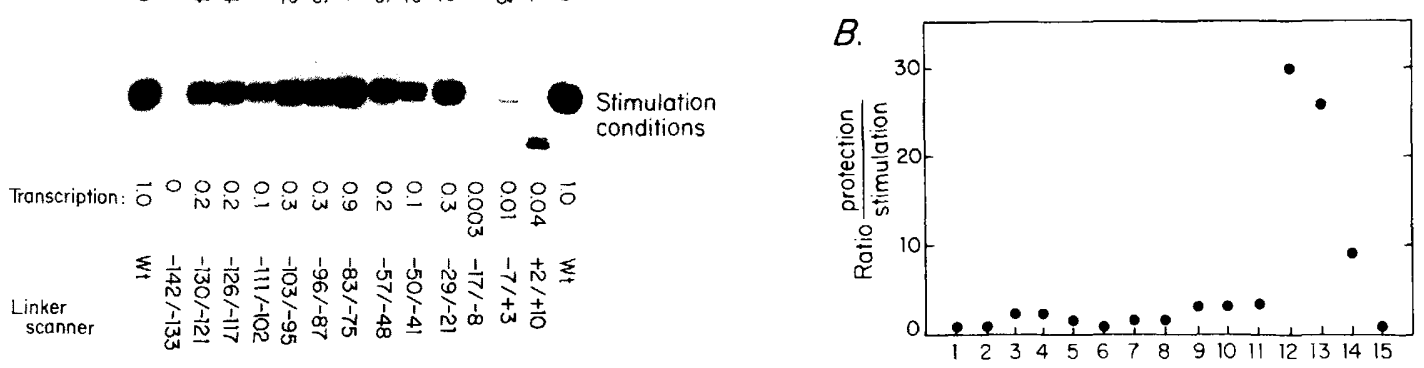

Figure 7. Transcription is more dependent on the core promoter domain under promoter stimulation conditions. $(A$, top) Assay of LS mutants of the promoter under protection conditions. Structure of the LS mutants (based on the wild-type promoter present in $\psi 40$ ) is described in Reeder et al. (1987). All templates were irradiated with UV and transcribed in unfractionated S-100 extract. The altered mobility of the signal band in lanes 13 and 14 is due to sequence divergence between the transcript and the S1 protection probe. The relative transcription signal from each mutant promoter is given immediately below each lane. $(A$, bottom) Assay of LS mutants under promoter stimulation conditions. $(B)$ Ratio of the transcription signal obtained under protection versus stimulation conditions.

was used, we observed that it accumulated transcripts at the same rate as the wild-type promoter for about the first $30 \mathrm{~min}$ of reaction. Transcription from the mutant promoter then leveled off. The time at which the signal from the promoter with the mutant terminator leveled off was the same as the time when readthrough transcripts began to accumulate. We interpret these results to mean that it takes $\sim 30 \mathrm{~min}$ for the polymerase to travel around the $3-\mathrm{kb}$ plasmid circle--an elongation rate of $\sim 2$ nucleotides per second. This elongation rate agrees with rates that we have measured previously in other in vitro situations (Hipskind and Reeder 1980; McKnight et al. 1980|. These results also agree with the interpretation that both promoters are equally capable of attracting factors and initiating transcription. It appears to be the act of reading through the promoter from upstream that damages initiation, and this cannot occur before the polymerase has had time to go completely around the plasmid circle. We conclude further, from Figure 8A, that multiple rounds of initiation must be occurring on most promoters in this reaction; otherwise, promoter occlusion could not be detected.

In Figure $8 \mathrm{~B}$ we show the time course of transcript accumulation under promoter stimulation conditions. Both wild-type and mutant promoters showed the same kinetics of transcript accumulation for the first hour. Transcription from the wild-type promoter then appeared to accelerate, whereas transcription from the mutant promoter remained constant. This result has been confirmed by pulse-labeling experiments (data not shown). In this time course we also UV-irradiated the templates to prevent any contribution from promoter protection. We conclude that under promoter stimulation conditions, as under protection conditions, the presence or absence of T3 has little effect on the initial ability of the promoter to attract factors and initiate transcription. Instead, the stimulation effect is due to some event that begins an hour after transcription has started. It is plausible that this event is the assembly of factors onto the initiation region of the promoter in a T3-dependent manner. In the linear phase of transcript accumulation, a wild-type template is transcribed with similar efficiency (within a factor of two) under either set of conditions.

\section{Discussion}

Two mechanisms for terminator-promoter interaction on a gene transcribed by RNA polymerase I

We demonstrated that the T3 termination element can cause increased initiation from the adjacent gene promoter by either of two distinct mechanisms. The first mechanism, promoter protection, is indirect because $\mathrm{T} 3$ simply prevents damage to the promoter by preventing elongating polymerase from reading through and dislodging the initiation complex. Consistent with this interpretation, artificial termination sites induced by UV irradiation can afford this protection as well as T3 does itself and the terminator can afford protection when located at any distance upstream of the promoter.

The second mechanism, promoter stimulation, is more direct and appears to involve physical interaction between a protein that binds to T3 (probably Rib 2) and a protein(s) that binds to the gene promoter (possibly xUBF; Pikaard et al. 1989). The hallmark of this interaction is that it requires precise spacing between the terminator and promoter. Any deviation from wild-type spacing is deleterious, but a partial rescue of activity occurs when the spacing is changed in integral units of $10 \mathrm{bp}$ (one turn of the DNA helix). These results in $X$. laevis are reminiscent of previous studies in bacteriophage $\lambda$, where it has been observed that $\lambda$ repressor molecules bind cooperatively to a pair of operator sites that 

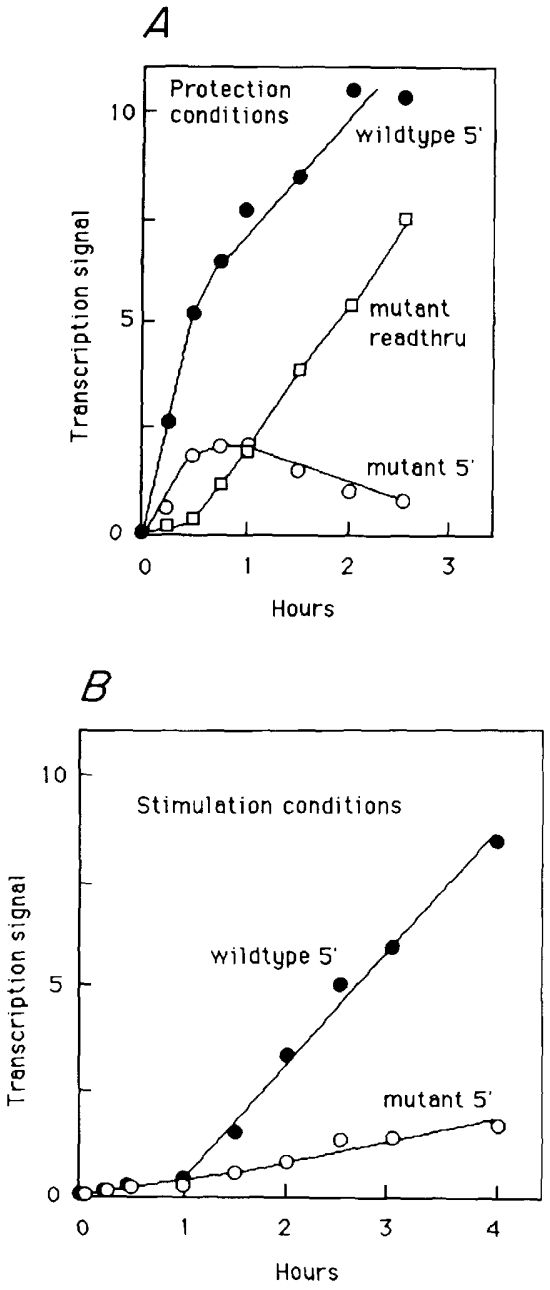

Figure 8. Time course of in vitro transcription promoter protection and stimulation conditions. $\{A\}$ Protection conditions. The plasmids pGem40 (wild-type) and pGemT3LS-7 (mutant) were transcribed independently under promoter protection conditions for varying times $(0,15,30,45,60,90,120$, and 150 $\mathrm{min}$ ) in an extract reconstituted by mixing the DEAE $0.35 \mathrm{M}$ and flowthrough fractions. The transcription initiation signal intensities from wild-type $(O)$ and mutant $|O|$ templates and the readthrough signal intensity from the mutant template $(\square)$ were quantified as described in Materials and methods and plotted against the time of the reaction. $(B)$ Stimulation conditions. The plasmids pGem40 (wild-type) and pGemT3LS-7 (mutant) were treated with UV and transcribed under promoter stimulation conditions for varying times $10,15,30,60,90,120$, $150,180$, and $240 \mathrm{~min})$. The transcription initiation signal intensities from wild-type $(0)$ and mutant $(0)$ templates were quantified and plotted against the time of the reaction.

are separated by five or six turns of the helix. Cooperativity is lost when the sites are separated by a nonintegral number of helical turns and the repressor molecules are no longer located on the same face of the helix (Hochschild and Ptashne 1986). A similar requirement for integral helical turn spacing has also been reported in the arabinose operon of Escherichia coli (Dunn et al. 1984).
What is the essential difference between protection and stimulation conditions?

Transcription conditions that allow promoter stimulation to function include preincubation of the extract with relatively large amounts of a nonspecific competitor DNA. Under these conditions, utilization of a subsequently added promoter is more efficient, presumably because incubation with nonspecific DNA removes many of the irrelevant DNA-binding proteins from the reaction. Lower template concentration also increases the likelihood that multiple DNA-binding proteins will interact with the same template. Assay of LS mutations of the promoter under stimulation conditions (Fig. 7) also shows an increased sensitivity to mutation of the initiation domain, suggesting a greater use of this domain. It is possible that protein bound to $\mathrm{T} 3$ can only interact with the promoter via contacts with transcription factors bound to the initiation domain. Alternatively, T3 and its bound protein may actively aid binding of factors to the initiation domain. Either way, it would appear from the time course (Fig. 8B) that it takes some time for this entire complex to be assembled in vitro. Once the association takes place, however, initiation in vitro proceeds at a considerably higher rate than previously. In the absence of $\mathrm{T} 3$, this complex is presumably never assembled and transcription initiation does not undergo an increase in rate. It is possible that stimulation conditions and proper association between $\mathrm{T} 3$ and the promoter are required for formation of a fully stable initiation complex.

Under protection conditions /high template concentration, no nonspecific competitor), utilization of promoter domains is clearly different. The $5^{\prime}$ domain around -140 is still strongly utilized, but the rest of the promoter is utilized to a lesser degree. We can speculate that because there is much less requirement for the initiation region, it is likewise not possible to detect any interaction between $\mathrm{T} 3$ and the initiation region. Under protection conditions, the only phenomenon that can be detected is the ability of $\mathrm{T} 3$ to prevent readthrough into the promoter.

\section{Detection of promoter protection and stimulation in} other polymerase I transcription systems

Phenomena similar to what we are calling promoter protection have been reported previously from several laboratories. Bateman and Paule (1988) have shown that when RNA polymerase I transcribes across the ribosomal gene promoter of Acanthamoeba, it disrupts a complex between the promoter and the transcription factor TIF. Similarly, Henderson et al. (1989) have shown that when polymerases from upstream transcribe into the mouse ribosomal gene promoter, the complex between the promoter and transcription factor $\mathrm{D}$ is disrupted.

The most convincing demonstrations of promoter protection have all come from experiments done in vitro (Bateman and Paule 1988; Henderson et al. 1989; this 
paper). Detection of promoter protection in vivo has been more variable, leading some workers to even doubt its existence (Firek et al. 1989). As examples of this in vivo variability, oocyte injection experiments cited in McStay and Reeder (1986) and in Firek et al. (1989) showed no decrease in transcription upon mutation of the T3 terminator. In contrast, experiments shown in Lucchini and Reeder (1989) showed a sharp drop in transcription with concomitant increase in readthrough upon mutation of T3. In X. laevis cultured kidney cells, we have shown that heat shock abolishes termination at T3 and leads to massive readthrough transcription on the endogenous ribosomal genes (Labhart and Reeder 1987). Despite the lack of termination, we were unable to detect any decrease in transcription initiation under heat shock conditions. In cultured human cells, heat shock also leads to a failure of polymerase I termination and increased readthrough on the endogenous genes (Parker and Bond 1989). In the human case, however, a large decrease in transcription initiation was also detected, consistent with damage to the initiation complex. Transient expression assays in mouse cells have given results entirely consistent with promoter-protection. Deletion of the promoter proximal terminator caused a drop in initiation and an increase in readthrough (Henderson et al. 1989). The negative effect of mutation of the terminator was completely reversed by UV irradiation of the template. We observed very similar effects of mutation of T3 when assayed by transient expression in cultured $X$. laevis kidney cells $(C$. Pikaard, unpubl.).

Some of this variability in detecting promoter protection can be understood if we accept the model in which elongation of polymerase damages transcription by dislodging transcription factors bound to the promoter. The severity of the drop in initiation will then depend on the frequency with which the initiation complex is disrupted and the rapidity with which it can reform after disruption. In vitro, where all reaction components are fairly dilute, reformation of the disrupted complex is probably quite slow. This may account for the fact that the clearest demonstrations of promoter protection have so far been in vitro. In vivo, where reactants are more concentrated, the ability to rapidly reform the initiation complex may depend on the precise physiology of the cell; this may account for the fact that we can obtain oocytes where promoter protection is easily demonstrated (Fig. 1A) and other oocytes where promoter protection is barely detectable (Fig. 2B).

Recently, Firek et al. (1989) reported that mutations in the $\mathrm{T} 3$ box reduce initiation twofold on templates that are injected into oocytes. It is possible that the effects they observed were due to promoter stimulation (as they did not observe a concomitant increase in readthrough upon mutation of the terminator). However, interpretation is complicated by the fact that they were injecting $X$. laevis templates into $X$. borealis oocytes. From the DNA sequence, it appears that the spacing between T3 and the promoter is $2 \mathrm{bp}$ farther apart in $X$. borealis than in X. laevis (La Volpe et al. 1983; Moss et al. 1985). It is known that both termination and promotion work reasonably well across species. It is unknown, however, whether the promoter stimulation effect would still function, because it is so sensitive to terminator-promoter spacing.

Terminator-promoter interactions on genes transcribed by RNA polymerase II

There is increasing evidence that terminators also act to protect RNA polymerase II promoters from damage due to readthrough transcription from upstream. For example, the placing of an active terminator between tandemly linked globin genes stimulates transcription from the downstream promoter (Proudfoot 1986). In some cases, readthrough disruption of a downstream promoter appears to serve as a regulatory mechanism. On the adenovirus genome, the gene for polypeptide IX is entirely contained within the ElB transcription unit and the polypeptide IX promoter is repressed by readthrough from the E1B promoter until after DNA replication (Vales and Darnell 1989). The Drosophila Adh gene possesses both a distal and a proximal promoter. The proximal promoter is active in first- to early third-instar larvae. The distal promoter then turns on and represses the proximal promoter by transcribing through it (Corbin and Maniatis 1989).

It is also possible that direct physical interaction (similar to the promoter stimulation described in this paper) can occur between polymerase II terminators and promoters. The adenovirus major late promoter contains a CCAAT motif that functions as an orientation-dependent termination element and is probably a binding site for a specific protein (Connelly and Manley 1989a,b). This CCAAT motif is only 75 bp upstream of the transcription initiation site for the major late promoter, a position suggesting that the protein bound to the motif might also interact with other transcription initiation factors.

T3 terminator is a domain of the $\mathrm{X}$. laevis ribosomal gene promoter

Previous studies have shown that the $X$. laevis ribosomal gene promoter is composed of several functional domains. The apparent requirement for these domains can vary markedly, depending on the precise assay conditions. Deletion mutagenesis (Sollner-Webb et al. 1983) located the $3^{\prime}$ boundary of the promoter as being near +6 , whereas finer point mutagenesis established it at +4 (Firek et al. 1990). Deletions from the 5 ' side established that accurate initiation could be directed with deletions as severe as -9 or -7 when these were injected into oocytes in relatively large amounts (Sollner-Webb et al. 1983; Windle and Sollner-Webb 1986b). This indicates that the frog promoter has a core promoter-similar to that observed with mammalian ribosomal gene promoters (as an example, see Miller et al. 1985) - that is capable of directing transcription on its own.

The frog promoter differs from the mammalian promoters, however, in having a much stronger require- 
ment for an upstream domain. Under most assay conditions, the frog promoter has an absolute dependence on a domain around -140 , both in oocyte injections and in vitro (Windle and Sollner-Webb 1986a; Reeder et al. 1987). This -140 domain shows up clearly under both promoter protection and promoter stimulation conditions in vitro (Fig. 7).

Sequence comparisons suggest that at a third region, from about -72 to -114 , there may be another functional domain, because this region shares strong homology with the enhancer elements located in the intergenic spacer. Requirement for the enhancer homology domain also appears to vary considerably, depending on the assay conditions (Windle and Sollner-Webb 1986a; Reeder et al. 1987).

We propose that the T3 terminator should also be considered as another functional domain of the promoter. In addition to its role as a terminator of transcription, the $\mathrm{T} 3$ domain can interact directly with at least one of the other promoter domains, possibly with the core domain, and can augment initiation by a mechanism that is not dependent on transcription termination. Interaction between $\mathrm{T} 3$ and the downstream domain requires precise spacing, as well as location of both elements on the correct face of the helix. Recently, Pape et al. (1990) showed that the domain at -140 must also be maintained on the correct face of the helix relative to the core domain. Changing the spacing between the -140 and core domains by one-half turn of the helix caused initiation at aberrant sites, whereas changing the spacing by integral turns of the helix maintained correct initiation. Combining our results with those of Pape et al. (1990) leads to the hypothesis that both $\mathrm{T} 3$ and the -140 domain interact with the core domain, and all three elements must be on the correct face of the helix for this interaction to take place.

\section{Does promoter stimulation involve handover of the polymerase from terminator to promoter?}

Models have been discussed in which a terminator might stimulate initiation by passing terminated polymerase directly to the gene promoter without releasing it to the free pool (Labhart and Reeder 1986). A related mechanism has also been proposed under the term readthrough enhancement (Mitchelson and Moss 1987); however, none of the effects described in this paper can be attributed to such mechanisms. Under promoter protection conditions, any polymerase I terminator, located at any distance upstream of the promoter, can cause protection and have the maximum positive effect. This distance independence does not seem compatible with a handover mechanism; neither does the fact that the maximum positive effect can be obtained after UV irradiation of the template. In a stimulation extract, the positive effect depends very sensitively on terminator placement, but the maximum positive effect is seen in the complete absence of polymerase approaching from upstream. In other words, the effect is seen when there is no polymerase to hand over.
In other work, we have also shown in two different in vivo assay systems that preventing polymerase from reaching the T3 terminator has no negative effect on initiation rates (Labhart and Reeder 1989; Lucchini and Reeder 1989). Therefore, we have failed so far to find any evidence for polymerase handover either in vivo or in vitro.

\section{Materials and methods}

Plasmid templates

The plasmids pGem 40 and pGem52 were constructed by the cloning of the $-245 /+50$ SalI-BamHI fragment of $\psi 40$ or the $-245 /+62$ Sall-BamHI fragment of $\psi 52$ (Labhart and Reeder 1984 ) into the Sall and BamHI sites of the vector pGEM3 (Promega). The SalI-BamHI fragment from pGem40 was also cloned into M13mp18. Single-stranded DNA from the resulting phage was used as a template for oligonucleotide-directed mutagenesis to create the series of T3 LS mutations shown in Figure 1. Oligonucleotide-directed mutagenesis was performed by the method of Kunkel (1985), by use of a mutagenesis kit supplied by Bio-Rad and following the manufacturer's instructions. The following oligonucleotides were used for mutagenesis:

After mutagenesis and sequence verification by dideoxy sequencing (Sanger et al. 1977), the mutated -245 to +50 SalIBamHI fragments were subcloned into the SalI and BamHI sites of pGem3 to give pGemT3LS-1, pGemT3LS-2, pGemT3LS-3, pGemT3LS-4, pGemT3LS-5, pGemT3LS-6, pGemT3LS-7, pGemT3LS-8, and pGemT3LS-11.

pGemPA 0 was constructed by the replacement of the $8 \mathrm{bp}$ between the SmaI sites at -166 and -158 in pGem40 with an 8-bp XbaI linker (5'-CTCTAGAG-3').

pGemPA +2 arose as a result of an artifact in the cloning of pGemPA 0 . The 8 bp between -166 and -158 was replaced by the sequence 5 '-CTCTCTAGAG-3'.

pGemPA +6 was constructed by digestion of pGemPA +2 with $X b a I$, filling in of the 4-base overhang with the Klenow fragment of DNA polymerase $I$, and recircularizing.

pGemPA - 5 was constructed by digestion of pGemPA + 2 with $\mathrm{XbaI}$, followed by $\mathrm{SI}$ nuclease treatment and recircularization.

pGemPA - 1 was constructed by replacement of the SalI$X b a I$ fragment of pGemPA 0 with that from the plasmid pGemT3 3' - 167 (a Bal 31 deletion mutant with $\mathrm{XbaI}$ linkers attached; B. McStay, unpubl.).

pGemPA - 10 was constructed by digestion of pGem40 with $B g I I$, followed by removal of the $3^{\prime}$ overhang with the Klenow fragment of DNA polymerase I and ligation of $X b a \mathrm{I}$ linkers $\left(5^{\prime}-\right.$ CTCTAGAG-3'). After digestion with Sall and XbaI, the -245 to -175 SalI-BglI fragment, with $X b a I$ linker attached, was used to replace the SalI-XbaI fragment of pGemPA 0.

pGemPA +10 was constructed by insertion of the annealed oligonucleotides 5'-CTAGACCGCT- $3^{\prime}$ and 5'-CTAGAGCGGT-3' into the XbaI site of pGemPA 0. 
pGemPA +15 was constructed by insertion of the annealed oligonucleotides $5^{\prime}$-CTAGACCGCCATGCT-3' and $5^{\prime}$-CTAGAGCATGGCGGT- 3 ' in to the $X b a l$ site of pGemPA 0.

pGemPA +20 was constructed by insertion of the annealed oligonucleotides 5' $5^{\prime}$-CTAGACGCCGGCATGGCGGT-3' and 5'-CTAGACCGCCATGCCGGCGT- $3^{\prime}$ into the $\mathrm{Xbal}$ site of pGemPA 0.

The DNA sequence between $\mathrm{T} 3$ and the promoter of the above pGemPA series plasmids (see Fig. 1) was determined by the method of Maxam and Gilbert (1980).

pTV-245T3-A was constructed by insertion of the -245 to +50 SaII-BamHI fragment into a modified pGem4 vector that contained a second T3 terminator (see McStay and Reeder 1990).

pTVT3LS-7T3-A was constructed by replacement of the $-245 /+50 \mathrm{SalI} / \mathrm{BamHI}$ fragment of pTV $-245 \mathrm{~T} 3-\mathrm{A}$ with the equivalent fragment from pGemT3LS-7.

\section{Oocyte injection}

Methods for injection of templates into $X$. laevis oocytes and assay of transcription by $S 1$ protection have been described previously (Labhart and Reeder 1984). A total of $2 \mathrm{ng}$ of template (1 $\mathrm{ng}$ of pGern52 control and $1 \mathrm{ng}$ of experimental template) was injected in a volume of $40 \mathrm{nl}$ into the nucleus of each oocyte, and 30-40 oocytes were pooled for RNA extraction after overnight incubation. The Sl probe is illustrated in Figure $1 \mathrm{C}$, and its structure is described below (see In vitro transcription conditions).

\section{S-100 extracts}

S-100 extracts were prepared from the $X$. laevis kidney cell line, $\mathrm{Xl}-\mathrm{K} 2$ (established by J. Roan, this laboratory) as described previously (McStay and Reeder 1986), except that cells were harvested with PBSA [145 mM NaCl, $4 \mathrm{~mm} \mathrm{Na}_{2} \mathrm{HPO}_{4}, 1 \mathrm{~mm}$ $\mathrm{KH}_{2} \mathrm{PO}_{4}(\mathrm{pH} 7.2) /$ containing $1 \mathrm{mM}$ EDTA in place of trypsin, and the final extract was dialyzed into $0.1 \mathrm{M} \mathrm{KCl}$ column buffer [CB100; $25 \mathrm{~mm}$ HEPES (pH 7.9), $100 \mathrm{~mm} \mathrm{KCl}, 0.1 \mathrm{~mm}$ EDTA, $20 \%$ glycerol $1 \mathrm{~mm}$ DTT, $0.5 \mathrm{mM}$ PMSF, and $1 \mathrm{mM}$ sodium metabisulfite)]. For some experiments, $\mathrm{S}-100$ extracts in $\mathrm{CB} 100$ were chromatographed over DEAE-Sepharose CL-6B (Pharmacia) to give a flowthrough fraction (DEAE flowthrough) and a fraction that elutes from the column with $0.35 \mathrm{M} \mathrm{KCl}$ (DEAE $0.35 \mathrm{M}$ ), as described in McStay and Reeder (1990).

\section{In vitro transcription conditions}

Promoter stimulation and protection can be observed both in unfractionated S-100 extracts and in partially fractionated extracts made by recombining the DEAE $0.35 \mathrm{M}$ and flowthrough fractions. The major variable dictating the type of response observed is the ratio of specific template to nonspecific competitor DNA.

Promoter protection conditions Twenty microliters of unfractionated S-100 extract (or alternatively, $20 \mu$ l of the DEAE 0.35 $\mathrm{M}$ fraction plus $10 \mu \mathrm{l}$ of DEAE flowthrough) and $400 \mathrm{ng}$ of supercoiled template were mixed and incubated on ice for $10 \mathrm{~min}$. Following the addition of $20 \mu \mathrm{l}$ of reaction buffer $[25 \mathrm{~mm}$ HEPES (pH 7.9), $80 \mathrm{~mm} \mathrm{KCl}, 12 \mathrm{~mm} \mathrm{MgCl}_{2}, 1 \mathrm{~mm}$ nucleotide triphosphates, $10 \mathrm{mM}$ creatine phosphate, $200 \mu \mathrm{g} / \mathrm{ml} \alpha$-amanitin, and $1 \mathrm{mM}$ DTT] supplemented with 20 units RNasin (Promega), the reaction was incubated at $25^{\circ} \mathrm{C}$ for $3 \mathrm{hr}$ (unless otherwise stated).

Promoter stimulation conditions Twenty microliters of unfractionated S-100 extract for alternatively, $20 \mu$ l of the DEAE
$0.35 \mathrm{M}$ fraction plus $10 \mu \mathrm{l}$ of DEAE flowthrough) and $200-400$ $\mathrm{ng}$ of the vector pGEM3 were mixed and incubated on ice for 10 min. Then 50-100 ng of supercoiled template was added, and the mixture was incubated on ice for an additional $10 \mathrm{~min}$. Following the addition of $20 \mu \mathrm{l}$ of reaction buffer, supplemented with RNasin (as above), the reaction was incubated at $25^{\circ} \mathrm{C}$ for $3 \mathrm{hr}$ (unless otherwise stated). To obtain the maximum promoter stimulation effect, it was necessary to determine empirically the optimum amount of nonspecific competitor and template for each extract.

Two polymerized double-stranded oligonucleotides, T3-B and T3-B mutant, were used as competitors in some transcription reactions. The sequence of the upper strand of T3-B is $5^{\prime}$ GATCCGCGGGGACTTGCTCGGCCG-3', and the sequence of the upper strand of T3-B mutant is 5'-GATCCGCGGAGATCTGCTCGGCCG-3'.

All reactions were stopped by the addition of $350 \mu \mathrm{l}$ of $0.15 \mathrm{M}$ $\mathrm{NaCl}, 50 \mathrm{~mm}$ Tris (pH 8.0), $6 \mathrm{mM}$ EDTA, $0.3 \mathrm{~m}$ sodium acetate, $0.1 \% \mathrm{SDS}$, and $100 \mu \mathrm{g} / \mathrm{ml} \mathrm{tRNA}$, followed by phenol/chloroform extraction and ethanol precipitation.

The probe used in $\mathrm{S} 1$ nuclease protection assays was prepared from the plasmid pGem 40 by digestion with Sall and BamHI, treatment with calf intestinal phosphatase, and labeling of $5^{\prime}$ ends with T4 polynucleotide kinase and $\left[\gamma^{32} \mathrm{P}\right]$ ATP $(3000$ $\mathrm{Ci} / \mathrm{mM})(3000 \mathrm{Ci} / \mathrm{mM}, \mathrm{NEN})$. The coding strand of the -245 to +50 Sall-BamHI fragment $\left\{5^{\prime}\right.$-labeled at +50$\}$ was purified on a $5 \%$ polyacrylamide strand-separating gel. S1 nuclease protection assays were performed as described previously (Labhart and Reeder 1986). Correctly initiated transcripts give rise to a protected probe fragment that is 50 nucleotides in length. Approximately $10^{5} \mathrm{cpm}$ of probe was used per assay.

Transcription signals were quantified by scanning autoradiographs with a Videk $1 \mathrm{~K} \times 1 \mathrm{~K}$ CCD camera, coupled with image analysis on a Sun $3 / 260$ computer (Sun Microsystems) with Visage 2000 software (Biolmage).

\section{UV treatment of transcription templates}

Transcription templates with UV lesions were prepared as follows. Supercoiled plasmids at $200 \mu \mathrm{g} / \mathrm{ml}$ in $10 \mathrm{mM}$ Tris (pH $7.51,0.1 \mathrm{mM}$ EDTA, were irradiated in a 96-well microtiter plate $(25 \mu \mathrm{l} /$ well). Irradiation was performed by use of a 25 -watt (254-nm peak) General Electric germicidal lamp (G25T8) for 5 $\mathrm{min}$ at $5000 \mathrm{~mW} / \mathrm{cm}^{2}$. The UV dose was measured with a Black Ray UV meter (UVP, model J-225).

\section{Acknowledgments}

We thank Judith Roan for technical assistance, Paul Goodwin for help with image analysis, and Ernie Tolentino for synthesis of oligonucleotides. This work was partially supported by National Institutes of Health grant GM-26624 to R.H.R.

The publication costs of this article were defrayed in part by payment of page charges. This article must therefore be hereby marked "advertisement" in accordance with 18 USC section 1734 solely to indicate this fact.

\section{References}

Bartsch, I., C. Schoneburg, and I. Grummt. 1988. Purification and characterization of TTFI, a factor that mediates termination of mouse ribosomal DNA transcription. Mol. Cell. Biol. 8: 3891-3897.

Bateman, E. and M. Paule. 1988. Promoter occlusion during rRNA transcription. Cell 47: 985-992.

Connelly, S. and J. Manley. 1989a. A CCAAT box sequence in the adenovirus major late promoter functions as part of an 
RNA polymerase II termination signal. Cell 57: 561-571. - 1989b. RNA polymerase II transcription termination is mediated specifically by protein binding to a CCAAT box sequence. Mol. Cell. Biol. 9: 5254-5259.

Corbin, V. and T. Maniatis. 1989. Role of transcriptional interference in the Drosophila melanogaster Adh promoter switch. Nature 337: 279-282.

Dunn, T.M., S. Hahn, S. Ogden, and R.F. Schlief. 1984. An operator at -280 base pairs that is required for repression of the ara $\mathrm{ABD}$ operon promoter: Addition of DNA helical turns cyclically hinders repression. Proc. Natl. Acad. Sci. 81: 5017-5020.

Firek, S., C. Read, D.R. Smith, and T. Moss. 1989. The Xenopus laevis ribosomal gene terminator contains sequences that both enhance and repress ribosomal transcription. Mol. Cell. Biol. 9: 3777-3784.

- 1990 . Point mutation analysis of the Xenopus laevis RNA polymerase I core promoter. Nucleic Acids Res. 18: 105-109.

Grummt, I., U. Maier, A. Ohrlein, N. Hassouna, and J-P. Bachellerie. 1985. Transcription of mouse rDNA terminates downstream of the $3^{\prime}$ end of 28S RNA and involves interaction of factors with repeated sequences in the $3^{\prime}$ spacer. Cell 43: $801-810$

Grummt, I., A. Kuhn, I. Bartsch, and H. Rosenbauer. 1986a. A transcription terminator located upstream of the mouse rDNA initiation site affects rRNA synthesis. Cell 47: 901911.

Grummt, I., H. Rosenbauer, I. Niedermeyer, U. Maier, and A. Oehrlein. 1986b. A repeated 18-bp sequence motif in the mouse rDNA spacer mediates binding of a nuclear factor and transcription termination. Cell 45: 837-846.

Hackett, P.B. and W. Sauerbier. 1975. The transcriptional organization of ribosomal RNA genes in mouse L cells. I. Mol. Biol. 91: 235-256.

Henderson, S. and B. Sollner-Webb. 1986. A transcriptional terminator is a novel element of the promoter of the mouse ribosomal RNA gene. Cell 47: 891-900.

Henderson, S.L., K. Ryan, and B. Sollner-Webb. 1989. The promoter-proximal rDNA terminator augments initiation by preventing disruption of the stable transcription complex caused by polymerase read-in. Genes Dev. 3: 212-223.

Hipskind, R.A. and R.H. Reeder. 1980. Initiation of ribosomal RNA chains in homogenates of oocyte nuclei. J. Biol. Chem. 255: 7896-7906.

Hochschild, A. and M. Ptashne. 1986. Cooperative binding of $\lambda$ repressors to sites separated by integral numbers of turns of the DNA helix. Cell 44: 681-687.

Kunkel, T.A. 1985. Rapid and efficient site-specific mutagenesis without phenotypic selection. Proc. Natl. Acad. Sci. 82: $488-492$.

Labhart, P. and R.H. Reeder. 1984. Enhancer-like properties of the $60 / 81$ bp elements in the ribosomal gene spacer of Xenopus laevis. Cell 37: 285-289.

- 1986. Characterization of three sites of RNA 3' end formation in the Xenopus ribosomal gene spacer. Cell 45: 431443.

- 1987. Ribosomal precursor 3' end formation requires a conserved element upstream of the promoter. Cell 50: $51-$ 57.

- 1989. High initiation rates at the ribosomal gene promoter do not depend upon spacer transcription. Proc. Natl. Acad. Sci. 86: 3155-3158.

1990. A point-mutation uncouples RNA 3 '-end formation and termination during ribosomal gene transcription in Xenopus laevis. Genes Dev. 4: 269-276.
La Volpe, A., M. Taggart, B. McStay, and A. Bird. 1983. DNase I-hypersensitive sites at promoter-like sequences in the spacer of Xenopus laevis and Xenopus borealis ribosomal DNA. Nucleic Acids Res. 11: 5361-5380.

Lucchini, R. and R.H. Reeder. 1989. A test of "polymerase handover" as a mechanism for stimulating initiation by RNA polymerase I. Nucleic Acids Res. 17: 373-387.

Maxam, A. and W. Gilbert. 1980. Sequencing end-labeled DNA with base-specific chemical cleavages. Methods Enzymol. 65: 499-525.

McKnight, S.L., R.A. Hipskind, and R.H. Reeder. 1980. Ultrastructural analysis of ribosomal gene transcription in vitro. J. Biol. Chem. 255: 7907-7911.

McStay, B. and R.H. Reeder. 1986. A termination site for Xenopus RNA polymerase I also acts as an element of an adjacent promoter. Cell 47: 913-920.

1990. A DNA-binding protein is required for termination of transcription by RNA polymerase I in Xenopus laevis. Mol. Cell. Biol. 10: 2793-3000.

Miller, K.G., J. Tower, and B. Sollner-Webb. 1985. A complex control region of the mouse rRNA gene directs accurate initiation by RNA polymerase I. Mol. Cell. Biol. 5: 554-562.

Mitchelson, K. and T. Moss. 1987. The enhancement of ribosomal gene transcription by recycling of RNA polymerase I. Nucleic Acids Res. 15: 9577-9596.

Moss, T. 1983. A transcriptional function for the repetitive ribosomal spacer in Xenopus laevis. Nature 302: 223-228.

Moss, T., K. Mitchelson, and R.F.J. De Winter. 1985. The promotion of ribosomal transcription in eukaryotes. In Oxford surveys on eukaryotic genes (ed. N. Maclean), vol. 2, pp. 207-250. Oxford University Press, Oxford.

Pape, L.K., J.J. Windle, and B. Sollner-Webb. 1990. Half helical turn spacing changes convert a frog into a mouse rDNA promoter: A distant upstream domain determines the helix face of the initiation site. Genes Dev. 4: 52-62.

Parker, K.A. and U. Bond. 1989. Analysis of pre-rRNAs in heatshocked HeLa cells allows identification of the upstream termination site of human polymerase I transcription. Mol. Cell. Biol. 9: 2500-2512.

Pikaard, C.S., B. McStay, M.C. Schultz, S.P. Bell, and R.H. Reeder. 1989. The Xenopus ribosomal gene enhancers bind an essential polymerase I transcription factor, xUBF. Genes Dev. 3: 1779-1788.

Proudfoot, N.J. 1986. Transcriptional interference and termination between duplicated $\alpha$-globin gene constructs suggests a novel mechanism for gene regulation. Nature 322: 562-565.

Reeder, R.H., D. Pennock, B. McStay, J. Roan, E. Tolentino, and P. Walker. 1987. Linker scanning mutagenesis of the Xenopus laevis ribosomal gene promoter. Nucleic Acids Res. 15: 7429-7441.

Sanger, F., S. Nicklen, and A.R. Coulson. 1977. DNA sequencing with chain terminating inhibitors. Proc. Natl. Acad. Sci. 74: 5463-5467.

Sollner-Webb, B., J.A.K. Wilkinson, J. Roan, and R.H. Reeder. 1983. Nested control regions promote Xenopus ribosomal RNA synthesis by RNA polymerase I. Cell 35: 199-206.

Vales, L.D. and J.E. Darnell, Jr. 1989. Promoter occlusion prevents transcription of adenovirus polypeptide IX mRNA until after DNA replication. Genes Dev. 3: 49-59.

Windle, J.J. and B. Sollner-Webb. 1986a. Two distant and precisely positioned domains promote transcription of Xenopus laevis rRNA genes: Analysis with linker-scanning mutants. Mol. Cell. Biol. 6: 4585-4593.

- 1986b. Upstream domains of the Xenopus laevis rDNA promoter are revealed in microinjected oocytes. Mol. Cell. Biol. 6: $1228-1234$. 


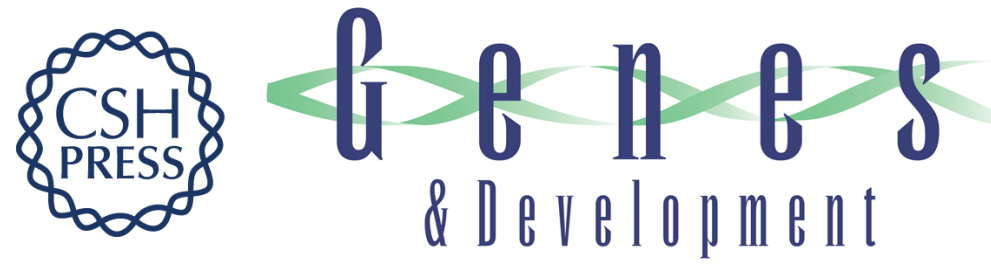

\section{An RNA polymerase I termination site can stimulate the adjacent ribosomal gene promoter by two distinct mechanisms in Xenopus laevis.}

B McStay and R H Reeder

Genes Dev. 1990, 4:

Access the most recent version at doi:10.1101/gad.4.7.1240

References This article cites 41 articles, 19 of which can be accessed free at: http://genesdev.cshlp.org/content/4/7/1240.full.html\#ref-list-1

License

Email Alerting Service

Receive free email alerts when new articles cite this article - sign up in the box at the top right corner of the article or click here.

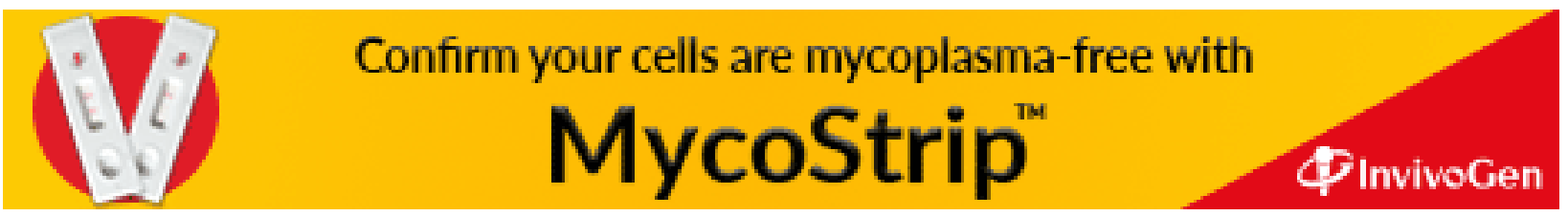

